\title{
The effects of a combined psychotherapy and physiotherapy group treatment program for survivors of torture incarcerated in an adult prison in Kurdistan, Iraq: A pilot study
}

\author{
April Gamble PT, DPT, CLT'1, Ahmed M. Amin Ahmed MBChB, MA, PhD², Salah \\ Hassan Rahim BSc ${ }^{3}$, Jeff Hartman PT, DPT, MPH ${ }^{4}$
}

\section{Key points of interest}

- Novel interdisciplinary treatment approach for incarcerated survivors of torture using a culturally and contextually appropriate physiotherapy and psychotherapy group treatment service

- Initial treatment effects on symptoms of mental health, physical health, and functioning are positive despite ongoing exposure to the stress and trauma of prison

- Reveals feasibility of implementing research that follows international research standards and practices within under-researched settings like prisons and post-conflict areas

\begin{abstract}
Introduction: Survivors of torture have high rates of mental health problems and can experience a sequela of physical effects with the most common being persistent pain. Similar to
\end{abstract}

1) Physiotherapy Technical Coordinator, Wchan Organization for Victims of Human Rights Violations; Founder of ACR - The American Center for Rehabilitation Correspondence to: april.dpt@gmail.com

2) Executive Director, Wchan Organization for Victims of Human Rights; Lecturer, Sulaimani Polytechnic University - Technical College of Health survivors of torture, persons that are incarcerated have high rates of mental health problems, persistent pain and pain-related disability. The purpose of this study is to assess the effect of an interdisciplinary group treatment approach, involving psychotherapy and physiotherapy, with survivors of torture whom are incarcerated in a prison in Kurdistan, Iraq.

Methods: A parallel group study design was used to compare a treatment group $(n=11)$ and a wait-list control group $(n=16)$. The treatment group participated in an interdisciplinary treatment service for a total of 10 weekly group sessions for each discipline. The primary outcome measures were symptoms of nociplastic pain, anxiety, depression, and PTSD. Secondary outcome measures evaluated physical functioning, sleep quality, and general self-efficacy.

Results: A statistically significant reduction in outcome measure scores was seen in all symptoms measured immediately post-treatment.

Discussion and Conclusion: These findings suggest that a culturally and contextually appropriate interdisciplinary group treatment intervention for survivors of torture in a prison

3) Mental Health Director, Wchan Organization for Victims of Human Rights

4) Assistant professor, University of Wisconsin School of Medicine and Public Health, Doctor of Physical Therapy program, Madison, WI. 
could be effective for short-term reductions in symptoms of anxiety, depression, PTSD, persistent pain, and function. The study has limitations including a small sample size, lack of long-term outcome measures, and an inability to isolate effect of each component of care. The study does demonstrate the feasibility of implementing research that follows international research standards and practices within underresearched settings and post-conflict areas.

Arabic and Kurdish versions of the abstract can be found at:

https://tidsskrift.dk/torture-journal/article/ view/119199

Keywords: Prisons, Pain, Mental Health, Physical Therapy, Psychotherapy

\section{Introduction}

Torture has been well documented to result in physical, psychological, and social consequences (Kabengele, Chastonay, \& Frey, 2014; Steel, et al., 2009; Weiss, et al., 2018; Williams, Peña, \& Rice, 2010). Survivors have high rates of mental health problems including symptoms consistent with post-traumatic stress disorder (PTSD), anxiety and depression (Steel et al., 2009) and can also experience a sequela of physical effects. The most common being persistent pain, specifically nociplastic pain which is described as pain that arises from changes in the nervous system with no clear evidence of actual tissue damage (Olsen et al., 2007; Tsur et al., 2017; IASP Terminology, 2017). It is theorized that a multitude of factors contribute to the development and maintenance of a sensitized nervous system that underlies nociplastic pain including fear avoidance behavior, deconditioning, unhelpful thoughts and beliefs about pain, and emotional distress (Asmundson et al., 2002; Asmundson \& Katz, 2009; Williams et al., 2010).
It is also well documented that incarceration results in physical, psychological, and social consequences. As Massoglia (2008) stated, incarceration exposes a person to traumatic stress which increases the risk of mental and physical health problems. Persons that are or have been incarcerated have higher rates of emotional distress and mental health problems including symptoms consistent with PTSD, anxiety, and depression (Dirkzwager, 2019; Fazel et al., 2016; Fazel \& Danesh, 2002; Fazel \& Seewald, 2012). Similar to survivors of torture, persons that are incarcerated also have higher rates of persistent pain and pain-related disability (Williams, et al., 2014; Darnall \& Sazie, 2012).

It has been established that physiological and psychological responses to pain, torture, and incarceration interact and contribute to comorbid conditions of mental health problems, stress reactions, persistent pain, and pain-related disability (Tsur, Shahar, Defrin, Lahav, \& Ginzburg, 2017; Tsur, Defrin, \& Ginzburg, 2017; Leder, 2018). Symptoms of PTSD, anxiety, and depression are associated with greater rates of physical health problems and pain-related disability (Tsang, et al., 2008; Bair at al., 2003). Similarly, $10-50 \%$ of persons receiving treatment for persistent pain reportedly have symptoms that satisfy the criteria for PTSD, compared to $8 \%$ in the general population (Asmundson et al., 2002). A mutual maintenance theory proposes that there are components of each condition that maintains or exacerbates symptoms of the other (Asmundson et al., 2002; Asmundson \& Katz, 2009).

The physical and psychological effects of torture and incarceration have a substantial burden on the individual, workforce, healthcare system, and society (Breivik et al., 2013; Sareen, 2014; Gifford, 2019; Wildeman et al., 2019; Kinner \& Young, 2018). This is related 
to decreased work productivity and high rates of healthcare utilization and disability (Breivik et al., 2013; Sareen, 2014). Considering the increased prevalence of health conditions in survivors of torture and persons that are incarcerated, and the burden of these conditions, finding effective and accessible treatment options should come with a sense of urgency (Penal Reform International, 2015).

Previous research established the effect of psychotherapy treatment on mental health symptoms in survivors of torture and persons that are incarcerated (Loughran \& King, 2004; Bunn et al., 2016; Yoon et al., 2017; Heckman et al., 2007). Physiotherapy, which integrates pain neuroscience education and other aspects of the biopsychosocial treatment of pain, has been used to treat persistent pain and functional impairments in the general population, those with mental health problems, and with survivors of torture (Amris \&Williams, 2015). Additionally, the effectiveness of an interdisciplinary approach, combining psychotherapy and physiotherapy, for the treatment of pain and mental health problems has been explored (Dibaj et al., 2017; Kurklinsky et al., 2016; Mcgeary, Moore et al., 2011). However, globally, there are no studies examining an interdisciplinary treatment program for survivors of torture who are incarcerated.

The purpose of this study is to assess the effect on symptoms of PTSD, anxiety, depression, persistent pain, and function of an established interdisciplinary group treatment approach, involving psychotherapy and physiotherapy, administered by Wchan Organization for Victims of Human Rights Violations (Wchan-pronounced wu-chan) with survivors of torture that are incarcerated in a prison in Kurdistan. It is hypothesized that the delivery of this culturally and contextually-designed treatment program will improve aspects of mental and physical health. A pilot study allows the researchers to explore the feasibility of conducting future research within the context of a prison in Kurdistan, including the implementation of internationally-recognized research practices and capacity building activities to equip locally trained healthcare professionals with the skills to conduct research activities.

\section{Methods}

\section{Research location and approval}

The study was conducted in a prison in the city of Sulaymaniyah in the semi-autonomous Kurdistan Region of Iraq (Kurdistan). This prison involved in this study houses in excess of 1200 men over 18 years of age incarcerated with sentences ranging from one month to life. The men in this prison are serving sentences for a variety of crimes including but not limited to murder, physical and sexual assault, terrorism, illegal drug use, marital infidelity, forgery, theft, and car accidents resulting in the physical harm of others. Wchan is recognized by the United Nations Refugee Agency (UNHCR) as a qualified mental health and psychosocial support services provider and has been providing services in the prison for over five years. To enhance the treatment, conditions, and available services, the prison has collaborated with national and international human rights organizations including Wchan, the International Committee of the Red Cross, the Independent Human Rights Commission of Kurdistan and Democracy and Human Rights Development Center.

Kurdistan has had reports that as high as $60 \%$ of males experience torture or ill treatment while in the criminal justice system (Heartland Alliance International, 2015).

Approval to perform research was granted by the prison director and by the Ethical Committee of the University of Sulaimani, College of Medicine. There is an institutional review 
board (IRB) and federal wide assurance available in Al-Najaf, Iraq. However, due to the political context, with Kurdistan acting as a semi-autonomous region of Iraq, it would not have been appropriate to engage this IRB and Kurdistan authorities would not recognize it as reflecting or representing their community. Finally, this study was internationally approved by the IRB through Northwestern University (Chicago, USA), (ID\# STU00206726; Clinical trials registry: NCT03470779).

\section{Research team}

A research team was formed with international and domestic scholars and domestic clinical healthcare professionals, including psychotherapists and physiotherapists trained in Kurdistan (see Annex 1). The treating clinicians met the local requirements for clinical practice which includes graduation from a 2-year or 4-year entry level degree program specific to the field. The clinical members of the team were providing treatment in the prison prior to the study. Additionally, prior to the study, the clinicians participated in a yearlong capacity building project to uptrain them in the delivery of the specific interdisciplinary treatment being studied.

The clinical team were instrumental in the development and design of the study to ensure that the procedures were culturally and contextually appropriate. They conducted all the study's recruitment procedures, data collection, and treatment interventions. The clinicians previous education and training did not include content related to conducting research. Therefore, to simultaneously build capacity of the research team and conduct a high caliber study, training and on-site supervision specific to research was provided by the primary author during and throughout the study.

\section{Study design}

A parallel group, randomized, wait-list controlled pilot study was used to compare a treatment group to a wait-list control group using an allocation ratio of $2: 3$. This allocation ratio was selected to account for potential dropouts within the wait-list control group.

\section{Recruitment, screening, and consent}

Recruitment for the study began in April 2018 and utilized a standard recruitment protocol for treatment at the prison which includes the use of trauma-informed practices. All activities related to the study were conducted in Kurdish Sorani. In summary, psychotherapists visited each living section within the prison and invited all to attend a seminar about the physical, psychological, and social symptoms of trauma and torture and the services offered by the organization that could potentially help address these symptoms. This seminar resulted in a potential cohort for treatment and a potential convenience sample for study.

Following participation in a seminar and expressing interest in receiving services, an individual was screened individually by a psychotherapist to determine if standard treatment services were appropriate (see Figure 1). If the individual demonstrated need, then the assessment continued and a standard psychotherapy intake was conducted which included two of the study's primary outcome measures; the Kurdish validated versions of the Harvard Trauma Questionnaire Part 4 (HTQ), the Hopkins Symptom Checklist-25 (HSCL-25) (see Table 1).The individual was referred for a physiotherapy assessment if they had symptoms consistent with post-traumatic stress disorder, anxiety, and/or depression evident by a total score of greater than or equal to 1.75 on HSCL-25 and/or by a total score greater than or equal to 2.5 on the HTQ. 
Prior to the standard physiotherapy assessment, the physiotherapist completed a chart review of the clinical documentation completed by the psychotherapist. This facilitated a trauma-informed assessment as the physiotherapist was aware of potential triggers, could avoid asking for the same information already attained by the psychotherapist, and was prepared to explore possible physical symptoms relevant to the case. A standard physiotherapist assessment includes the Central Sensitization Inventory Part A which served as a primary outcome measure for the study (See Table 1).

After completing these components, those that met inclusion criteria (see Table 2) were invited to participate. The process of in- formed consent was adapted to the context and culture by only requiring verbal consent and not written consent. The participants that provided informed consent for the study participated in a second individual session with a physiotherapist to complete data collection specific to the research study. This included the following secondary outcome measures: (1) Patient Specific Functional Scale; (2) Pittsburgh Sleep Quality Index; and (3) General Self-Efficacy Scale. For individuals not interested in participating in the study, the physiotherapist completed the remaining components of the standard physiotherapy assessment and enrolled the individual in the appropriate standard treatment services.

Table 1. Clinical data that was collected as a part of the standard treatment protocol

Psychotherapy Intake Physiotherapy intake During treatment

- Name

- Age

- Date of birth

- Place of birth

- Ethnicity

- Religion

- Education

- Ex-occupation

- Occupation

- Marital status

- Number of children

- Date arrested

- Duration in detention

- Period of charge

- History of psychiatric treatment

- Details of torture history

- Consent for treatment

- Information required for risk assessment

- HTQ

- HSCL-25
- Open ended interview of - Subjective feedback and symptoms and functional comments problems

- Body chart

- Attendance of treatment sessions

- Medical Screening checklist - Clinical assessment of

- Symptom checklist

- Objective evaluation as deemed necessary by physiotherapist

- Central Sensitization Inventory Part A participants in the treatment group for the completion of the regular treatment notes by the psychotherapists and physiotherapists. 
Table 2. Inclusion and Exclusion criteria

\begin{tabular}{ll}
\hline Inclusion & Exclusion \\
\hline Age equal to or greater than 18 years. & $\begin{array}{l}\text { Would not remain in the current prison } \\
\text { for at least } 6 \text { months from the onset of the } \\
\text { study by self-report. }\end{array}$ \\
\hline $\begin{array}{l}\text { Incarcerated in the prison where research is } \\
\text { conducted. }\end{array}$ & $\begin{array}{l}\text { Was unable to make the time commitment } \\
\text { required to participate. }\end{array}$ \\
\hline $\begin{array}{l}\text { Native speaker of Sorani, a Kurdish lan- } \\
\text { guage. }\end{array}$ & $\begin{array}{l}\text { Per treating psychotherapist, presented with } \\
\text { symptoms consistent with a psychiatric } \\
\text { condition and/or high risk to self or others } \\
\text { which made participation in the study }\end{array}$ \\
& unsafe. \\
\hline $\begin{array}{l}\text { History of torture is self-reported and docu- } \\
\text { mented per the UNCAT definition. }\end{array}$ & $\begin{array}{l}\text { Per treating physiotherapist, presented with } \\
\text { symptoms consistent with or previously } \\
\text { diagnosed with a severe medical condi- } \\
\text { tion which made participation in the study } \\
\text { unsafe. }\end{array}$ \\
\hline
\end{tabular}

Presented with symptoms consistent with post-traumatic stress disorder, anxiety, and/ Reported previously receiving treatment by or depression evident by a total score of greater than or equal to 1.75 on Hopkins Symptoms Checklist-25 and/or by a total score greater than or equal to 2.5 on the Harvard Trauma Questionnaire Part 4.

Presented with symptoms consistent with persistent nociplastic pain evident by a score of greater than or equal to 40 on the Central Sensitization Inventory Part A.
Current substance abuse reported by participant or identified by treating psychotherapist.

Reported currently receiving mental health services and/or physiotherapy services from other organization.

Reported unresolvable conflict with individual/s enrolled in the study.

\section{Population}

Participants were all incarcerated in the prison and male survivors of torture based on the UNCAT definition of torture (Convention against Torture and Other Cruel, Inhuman or Degrading Treatment or Punishment - Ad- dendum to Initial reports of States parties due in 1995, 1995). As part of standard treatment protocol, self-reported history of torture was identified through a verbal one-on-one open question interview conducted by a psychotherapist and documented on an original 
form.

\section{Intervention Procedures}

Originally Wchan provided only psychotherapy services within the prison, but the interdisciplinary approach being studied was adopted in 2017 as clients that received psychotherapy treatment reported persistent difficulties with pain, sleep, somatic symptoms, and physical functioning, as well as, a desire for body-based coping strategies. The structure of the interdisciplinary treatment as described here allows for close collaboration between the treating physiotherapists and psychotherapists so as to collaboratively support the clients' emotional, physical, and social functioning, while also maintaining distinct professional role and responsibilities.

Treatment manuals for the standard interdisciplinary treatment program were originally developed by the Center for Victims of Torture and then adapted and implemented to be more effective for the specific context and culture. The clinicians follow this treatment manual which includes specific treatments but are also able to modify them based on their clinical judgement and the needs of the clients. See Table 3 for details of the treatment sessions.

Given the small sample size of the study and that the severity of depression and anxiety has the potential to confound treatment response, proportionate stratified random sampling was used. To do this, the enrolled participants were first stratified into two strata based on their total baseline score on the HSCL-25 which reflects symptoms of anxiety and depression (Strata 1: low total score; Strata 2: high total score). The cut-off value for the two strata was established based on a review of data from 154 persons that previously received treatment services and nearly all had depression/anxiety. The participants randomly assigned to one of two groups: (1) treatment or (2) wait-list. To perform random selection, the code numbers of each strata were inserted into a list randomizer application (https://www.random. org/lists/). This generated two lists. The code numbers of the participants identified via this randomly-generated list were the participants assigned to the treatment group from each stratum. Participants were randomly selected for the treatment group from strata one and from strata two so that equal proportions of people with high and low HSCL-25 total scores were assigned in each group at baseline.

Twelve participants were assigned to the treatment group. To account for potential dropouts, 18 were assigned to the wait-list group. Participants of the treatment group received 10 weekly group psychotherapy treatment sessions and 10 weekly group physiotherapy treatment sessions, and one individual check-in session for physiotherapy and psychotherapy over a span of 11 weeks. Participants in the wait-list group did not receive any treatment until after the completion of the study but did participate in an individual check-in session with a psychotherapist during weeks 6 and 7 of the intervention to assess for risk. Per standard treatment protocol and to ensure coordinated care, the clinical research team had an interdisciplinary meeting before the start of the treatment sessions, between sessions 5 and 6 , and after the completion of the treatment sessions. During the treatment period, participants did not have access to any additional direct mental health services.

As per the previously established manual, treatments provided in the physiotherapy group treatment include the following: (1) relaxation exercises; (2) mindfulness exercises; (3) breathing exercises; (4) stretching and strengthening exercises; (5) low to moderate intensity exercise; (6) therapeutic neuroscience education; (7) circuit training; (8) body 
Table 3. Details of the Interdisciplinary Group Treatment Service

\begin{tabular}{lll}
\hline Session & Physiotherapy & Psychotherapy \\
\hline 1 & - Introductions & - Introductions \\
& - Establishing group agreement & - Discussing expectations \\
& - Relaxed diaphragmatic breathing & - Establishing group agreement \\
& - Intervals of low to moderate intensity exer- & - Psychoeducation: One finger vs. \\
& - Selecting individual physical, psychological, & - Closing the circle \\
& and social goals & \\
\hline 2 & - Home practice check-in & - Home practice check-in \\
& - Intervals of low to moderate intensity exer- & - Exploring strengths and challenges \\
& cise and diaphragmatic breathing & - Cognitive triangle \\
& - Body awareness activity & - Psychoeducation: negative vs posi- \\
& - Stretches for the chest musculature & tive thinking \\
& - Progressive muscle relaxation & - Closing practice
\end{tabular}

\begin{tabular}{|c|c|c|}
\hline 3 & $\begin{array}{l}\text { - Home practice check-in } \\
\text { - Therapeutic neuroscience education: } \\
\text { Posture and emotions } \\
\text { - Active exercise for postural awareness } \\
\text { - Therapeutic neuroscience education: } \\
\text { Posture and movement variability } \\
\text { - Intervals of moderate to high intensity exer- } \\
\text { cise and diaphragmatic breathing } \\
\text { - Progressive muscle relaxation }\end{array}$ & $\begin{array}{l}\text { - Home practice check-in } \\
\text { - Movement breathing } \\
\text { - Exploring emotions and linking them } \\
\text { with physical sensations } \\
\text { - Closing practice }\end{array}$ \\
\hline 4 & $\begin{array}{l}\text { - Home practice check-in } \\
\text { - Intervals of moderate to high intensity exer- } \\
\text { cise and diaphragmatic breathing } \\
\text { - Therapeutic neuroscience education: Step- } \\
\text { ping on a nail, Temperature warning light } \\
\text { - Therapeutic exercise for back } \\
\text { - Progressive muscle relaxation }\end{array}$ & $\begin{array}{l}\text { - Home practice check-in } \\
\text { - Narrative Exposure Therapy 1: The } \\
\text { River of Life Exercise } \\
\text { - Closing practice }\end{array}$ \\
\hline $\begin{array}{l}\text { Individual } \\
\text { check-in }\end{array}$ & $\begin{array}{l}\text { - Conduct body chart and the Central Sensi- } \\
\text { tization Inventory Part A } \\
\text { - Provide individualized education and exer- } \\
\text { cise prescription based on the physiothera- } \\
\text { pists' clinical judgement } \\
\text { - Address any questions or concerns }\end{array}$ & $\begin{array}{l}\text { - Discuss and concerns about sharing } \\
\text { traumatic experiences } \\
\text { - Risk assessment } \\
\text { - Provide individualized psychoeduca- } \\
\text { tion based on the psychotherapist's } \\
\text { clinical judgement } \\
\text { - Address any questions or concerns }\end{array}$ \\
\hline
\end{tabular}




\begin{tabular}{|c|c|c|}
\hline Session & Physiotherapy & Psychotherapy \\
\hline 5 & $\begin{array}{l}\text { - Home practice check-in } \\
\text { - Therapeutic exercise for lower extremities } \\
\text { - Therapeutic neuroscience education: Cups } \\
\text { of water, Factors contributing to sensitivity } \\
\text { - Intervals of moderate to high intensity exer- } \\
\text { cise and diaphragmatic breathing } \\
\text { - Body scan mindfulness technique }\end{array}$ & $\begin{array}{l}\text { - Home practice check-in } \\
\text { - Review confidentiality agreement } \\
\text { - Discuss respectful responses to } \\
\text { others, listening to others empathi- } \\
\text { cally } \\
\text { - Narrative Exposure Therapy 2: Dis- } \\
\text { cussion of Traumatic Experiences } \\
\text { - Containment and integration } \\
\text { - Closing practice }\end{array}$ \\
\hline 6 & $\begin{array}{l}\text { - Home practice check-in } \\
\text { - Therapeutic exercise for upper extremities } \\
\text { - Intervals of moderate to high intensity exer- } \\
\text { cise and diaphragmatic breathing } \\
\text { - Therapeutic neuroscience education: Finding } \\
\text { comfort during sleep, lifting, and carrying } \\
\text { - Body scan mindfulness technique }\end{array}$ & $\begin{array}{l}\text { - Home practice check-in } \\
\text { - Review confidentiality agreement } \\
\text { - Narrative Exposure Therapy 2: Dis- } \\
\text { cussion of Traumatic Experiences } \\
\text { - Large group reflection and contain- } \\
\text { ment of trauma reactions } \\
\text { - Closing practice }\end{array}$ \\
\hline 7 & $\begin{array}{l}\text { - Home practice check-in } \\
\text { - Functional goal check-in } \\
\text { - Intervals of moderate to high intensity exer- } \\
\text { cise and diaphragmatic breathing } \\
\text { - Therapeutic neuroscience education: Wrin- } \\
\text { kles } \\
\text { - Body scan mindfulness technique }\end{array}$ & $\begin{array}{l}\text { - Home practice check-in } \\
\text { - Surviving multiple losses } \\
\text { - Psychoeducation: Self-blame, guilt, } \\
\text { and shame } \\
\text { - Coping strategies for self-blame } \\
\text { related to grief } \\
\text { - Closing practice }\end{array}$ \\
\hline 8 & $\begin{array}{l}\text { - Home practice check-in } \\
\text { - Circuit training } \\
\text { - Therapeutic neuroscience education: } \\
\text { Develop a coping plan - Part one } \\
\text { - Progressive muscle relaxation or body scan } \\
\text { mindfulness technique (per participants' } \\
\text { request) }\end{array}$ & $\begin{array}{l}\text { - Home practice check-in } \\
\text { - Ambiguous loss } \\
\text { - Expressing multiple losses through } \\
\text { storytelling } \\
\text { - Rebuilding life after loss } \\
\text { - Closing practice }\end{array}$ \\
\hline 9 & $\begin{array}{l}\text { - Home practice check-in } \\
\text { - Circuit training } \\
\text { - Therapeutic neuroscience education: } \\
\text { Develop a coping plan - Part two } \\
\text { - Therapeutic exercise for the neck and upper } \\
\text { back } \\
\text { - Progressive muscle relaxation or body scan } \\
\text { mindfulness technique (per participants' } \\
\text { request) }\end{array}$ & $\begin{array}{l}\text { - Home practice check-in } \\
\text { - Adapted Tree of Life } \\
\text { - Future goals } \\
\text { - Closing practice }\end{array}$ \\
\hline 10 & $\begin{array}{l}\text { - Home practice check-in } \\
\text { - Therapeutic neuroscience education: Sleep } \\
\text { hygiene } \\
\text { - Therapeutic exercise - Demonstration and } \\
\text { sharing } \\
\text { - Celebration ceremony }\end{array}$ & $\begin{array}{l}\text { - Home practice check-in } \\
\text { - Review coping skills: Keep, start, stop } \\
\text { plan } \\
\text { - Letter to the future group } \\
\text { - Closing practice } \\
\text { - Celebration ceremony }\end{array}$ \\
\hline
\end{tabular}




\begin{tabular}{|c|c|c|}
\hline Name & Description & Psychometric properties \\
\hline $\begin{array}{l}\text { Harvard } \\
\text { Trauma Ques- } \\
\text { tionnaire Part } 4 \\
(\text { HTQ)^ }\end{array}$ & $\begin{array}{l}\text { Part } 4 \text { is a self-reported checklist that in- } \\
\text { cludes } 30 \text { trauma symptoms with the first } \\
16 \text { items being derived from the DSM- } \\
\text { IIIR/DSM-IV criteria for PTSD and the } \\
\text { other } 14 \text { items describe symptoms related } \\
\text { to specifically refugee trauma. The scale for } \\
\text { each question includes four categories of } \\
\text { response: "Not at all," "A little," "Quite a } \\
\text { bit," "Extremely," rated } 1 \text { to } 4 \text {, respectively. } \\
\text { A scientifically validated cut-off score of } \\
\text { greater than or equal to } 2.5 \text { has been es- } \\
\text { tablished. }\end{array}$ & Cronbach's alpha: $.86-.89^{a}$ \\
\hline
\end{tabular}

Hopkins $\quad$ A 25 item self-reported symptom inventory

Symptom

Checklist-25

$\left(\right.$ HSCL-25) ${ }^{\star}$

Central Sensitization Inventory Part $\mathrm{A}^{\star \star}$ which measures symptoms of anxiety and depression. The scale for each question includes four categories of response: "Not at all," “A little," "Quite a bit," "Extremely," rated 1 to 4 , respectively. A scientifically validated cut-off point has been established at less than or equal to 1.75 for asymptomatic people.

A 25 item self-report outcome measure designed to identify persons who have symptoms that may be related to central sensitization and nociplastic pain. The scale for each question ranges from 0 (never) to 4 (always).
Cronbach's alphab: .73-.93

Pearson correlation coef-

ficient $^{\mathrm{b}}: .73-.86$

Cronbach's alpha: $0.91^{\mathrm{d}}$

Test-retest reliability $=$ $0.817^{\mathrm{c}}$
Patient Specific Functional Scale ${ }^{\star \star}$
A self-report outcome measure of function for a large number of clinical presentations. Persons identify important activities they are unable or having difficulty performing as a result of their problem. They then rate (on an 11-point scale) the current level of difficulty associated with each activity with " 0 " representing "unable to perform" and "10" representing "able to perform at prior level."
Valid, reliable, and responsive in populations multiple pain presentations including chronic low back pain and for individuals with a limited number of acute, subacute, and chronic conditions. $^{\mathrm{e}}$ 


\begin{tabular}{|c|c|c|}
\hline Name & Description & Psychometric properties \\
\hline $\begin{array}{l}\text { Pittsburgh } \\
\text { Sleep Quality } \\
\text { Index } \star \star\end{array}$ & $\begin{array}{l}\text { A } 19 \text { item self-rated questionnaire grouped } \\
\text { into seven component scores (subjective } \\
\text { sleep quality, sleep latency, sleep duration, } \\
\text { sleep efficiency, sleep disturbance, hypnotic } \\
\text { medication use, and daytime dysfunction). } \\
\text { The seven component scores combine to } \\
\text { provide a global PSQI score with an es- } \\
\text { tablished cutoff score with scores greater } \\
\text { than or equal to } 5 \text { indicating subjective } \\
\text { insomnia. }\end{array}$ & $\begin{array}{l}\text { Cronbach's alpha: } 0.70- \\
0.83^{\mathrm{f}} \\
\text { Intraclass correlation coef- } \\
\text { ficient: } .79-.83^{\mathrm{f}}\end{array}$ \\
\hline $\begin{array}{l}\text { General } \\
\text { Self-Efficacy } \\
\text { Scale }^{\star \star}\end{array}$ & $\begin{array}{l}\text { A } 10 \text { item self-report measure of self-effi- } \\
\text { cacy that is designed to assess optimistic } \\
\text { self-beliefs to cope with a variety of diffi- } \\
\text { cult demands in life. Possible responses are } \\
\text { not at all true (1), hardly true (2), moder- } \\
\text { ately true (3), and exactly true (4), yielding } \\
\text { a total score between } 10 \text { and } 40 .\end{array}$ & $\begin{array}{l}\text { Cronbach's alpha: .76- } .90^{\mathrm{g}} \\
\text { The total score is correlated } \\
\text { to emotion, optimism, and } \\
\text { work satisfaction. }^{\mathrm{g}} \\
\text { Negative coefficients were } \\
\text { found for depression, stress, } \\
\text { health complaints, burnout, } \\
\text { and anxiety. }\end{array}$ \\
\hline
\end{tabular}

^Measure was translated, culturally adapted, validated and used in previous research by an external group (Bolton, P., Bass, J, Zangana, G., et al. (2014),

${ }^{\star}$ Measure was translated internally with the translation not having been validated. Reported psychometric properties relate to the original English version.

${ }^{a}$ Rasmussen et al. (2015), bBolton et al. (2014), ${ }^{\mathrm{c}}$ McKernan et al. (2019), ${ }^{\mathrm{d}}$ Mayer et al. (2012), ${ }^{\mathrm{e}}$ Horn et al. (2012), ${ }^{\mathrm{f}}$ Mollayeva et al. (2015), ${ }^{\mathrm{g}}$ Schwarzer \& Jerusalem (1995)

awareness exercises; and (9) interactive education regarding coping skills, sleep, mind-body connection, and other topics. As per the previously established manual, the psychotherapy group treatment includes the following: (1) stabilization techniques and coping skills; (2) breathing and mindfulness exercises; (3) psychoeducation; (4) techniques based on dance movement therapy and somatic psychology; (5) techniques based on cognitive behavioral therapy; (6) techniques from narrative exposure therapy; (6) strategies for reflecting on loss and grief including ambiguous loss; and (7) goal setting and planning for the future.

Data collection and analysis
Data collected for research purposes were mostly a component of standard clinical treatment protocol. Clinical documentation using individual patient files is a standard part of clinical care and the participating psychotherapists and physiotherapists are well-trained in requesting and using information in a trauma-informed manner. All data collection activities were conducted in Kurdish Sorani and with measures translated and culturally adapted for Kurdish Sorani speakers, with two of the measures having been scientifically validated (see Table 4). Additionally, they were conducted privately, with the exception of documenting the subjective feedback that is shared during the therapeutic process within 
the group treatment sessions. Participants had several individual sessions with clinical staff in order to allow them to discuss any private matters that they felt uncomfortable discussing in a group setting. Data collection was not blinded as this was not feasible due to the logistical procedures required in the prison and a small amount of staff being granted access in the prison.

The primary outcome measures evaluated symptoms of anxiety, depression, PTSD, nociplastic pain. The secondary outcome measures evaluated physical functioning, sleep quality, and general self-efficacy (see Table 4). As these are commonly used clinically and in research for similar populations they were selected so as to inform the selection of feasible measures for a future large-scale study. Additionally, the primary outcome measures were already included as part of standard treatment protocol. All measures were patient-reported and were administered with versions that were translated to Kurdish Sorani, with two measures, HTQ Part 4 and HSCL-25, having been culturally adapted and validated in this language and for this specific population (Bolton, Bass, Zangana, Kamal, Murray, Kaysen, ... Rosenblum. 2014). The other measures have not been previously validated in Kurdish Sorani as this was not feasible with the group's limited resources. However, before the study and as a component of program development, all measures underwent an internal multi-step translation process to strive for a valid, reliable, and culturally appropriate translation.

Additional clinical data collected during the psychotherapy intake session and physiotherapy assessment as a part of standard treatment protocol was not included in the study's data analysis due to the small sample size limiting its usefulness (See Table 1).

For data analysis purposes, information from the written documentation was trans- ferred to an electronic spreadsheet by the research team and stored on a removable media device with encryption. Following the study's final data collection, data analysis was conducted using PASW 18.0 (SPSS Inc., Chicago, IL). Given the small sample size, non-parametric statistical tests were used. For dependent variables, within-groups effects were analyzed using the Wilcoxon signed-rank test, and between-groups effects were analyzed using the Mann-Whitney U test. Data were analyzed from Baseline (T0) to Post-Treatment (T1) to assess effects. The level of statistical significance was set a priori at $\mathrm{p}<0.01$.

\section{Results}

\section{Participant selection}

After the recruitment seminar was conducted, 115 individuals expressed interest in participating. Of those, 68 persons did not meet inclusion and exclusion criteria based on information gathered during the screening sessions. The remaining 47 were assessed further for eligibility. 30 met the study criteria and were invited and selected for study. Recruitment and pre-testing (T0) occurred between April $5^{\text {th }}$ and June $28^{\text {th }}, 2018$. The intervention began July $3^{\text {rd }}$ and continued for a total of 11 consecutive weeks of service. The posttesting (T1) was completed by September $27^{\text {th }}, 2018$. See Figure 1 for more details.

\section{Participant demographics}

The mean age of the participants was 33.2 years. The duration of the prison sentences ranged from three years to life with two persons in each group having life sentences. All participants were survivors of torture. The most common forms of torture reported by the participants included verbal abuse, electrical shock, solitary confinement, suspension, hitting with instruments like pipes, sticks, and 
cables, and kicking, slapping, and punching. The two groups, with the dropouts excluded, were examined prior to comparing changes in the means. They were equivalent based on demographics and baseline measures used except for the PSQI global, with the wait-list group having a higher mean score but both groups demonstrating clinically significant sleeping problems per the measure's established cut-off score.

\section{Outcomes}

The primary outcome measures in this study were symptoms of persistent nociplastic pain,

Figure 1. Flow Chart of Study Participants

id not met criteria $(n=17)$

- Low scores on HSCL and/or HTQ $(n=7)$

- Low sc ores on CSI $(n=7)$

- Illegal drug use $(\mathrm{n}=1)$

- Requested individual treatment $(n=1)$

- Transferred to another prison before enrollment $(n=1)$

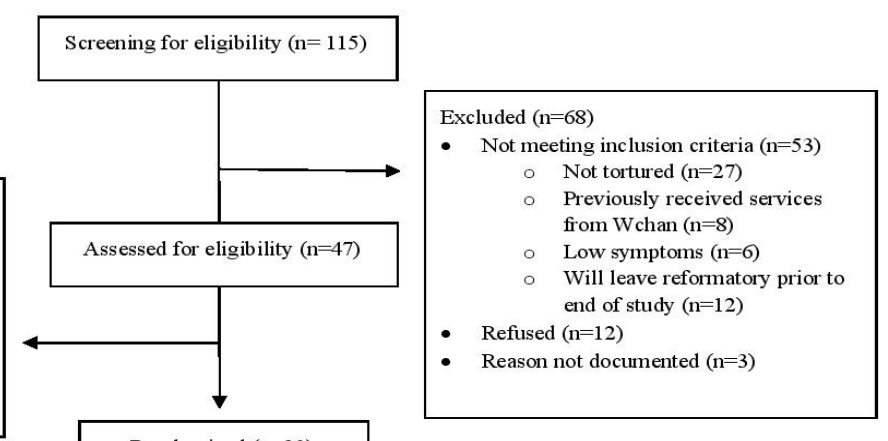

Randomized $(\mathrm{n}=30)$

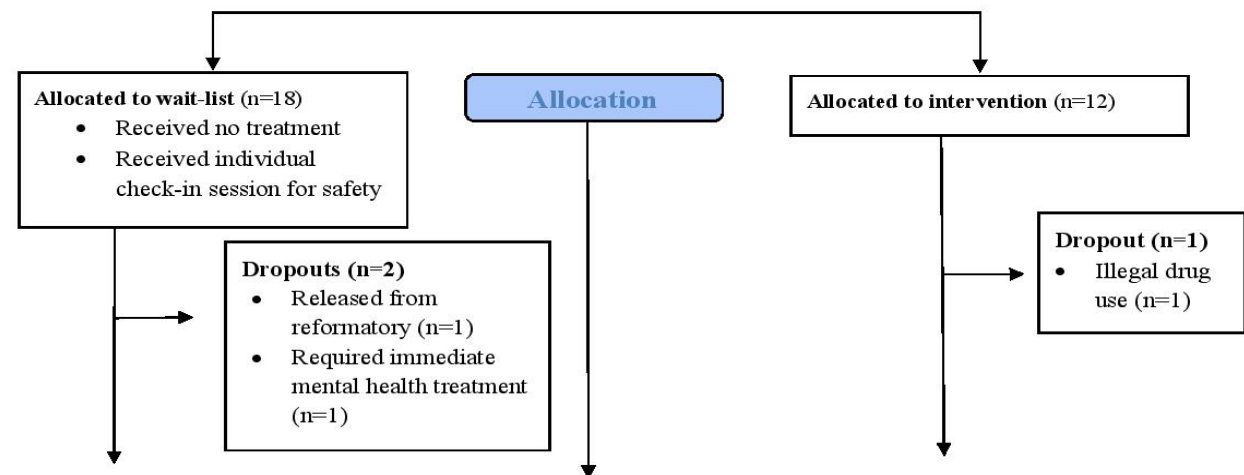

Assessments $(n=16)$

- 16 completed baseline and post-treatment



Analysed $(n=16)$
Post-Treatment Testing

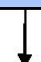

Analysis
Assessments $(\mathrm{n}=11)$

- 11 completed baseline and post-treatment assessments

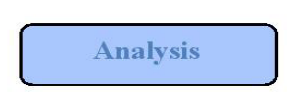

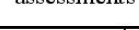

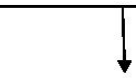

Analysed $(\mathrm{n}=11)$ 
anxiety, depression, post-traumatic stress disorder. These were based on, respectively, Central Sensitization Inventory Part A (CSI), Hopkins Symptom Checklist-25 (HSCL-25), and Harvard Trauma Questionnaire Part 4 (HTQ).

Statistically significant improvement was seen in the treatment group in all measures. The change in treatment group $(n=11)$ scores were statistically significantly greater than the wait list group $(n=16)$ across all measures (see Table 5).

Statistically significant within-group improvement was seen in the treatment group in all measures. The change in treatment group scores were statistically significantly greater than the wait list group across all measures (see Table 5). All participants in both groups initially met criteria to be considered symptomatic with anxiety and/or depression. At post, 15 out of 16 participants in the wait-list group met this criterion and 0 out of 11 in the treatment group. At baseline, 13 participants in the wait-list group and 8 in the treatment group met criteria for post-traumatic stress disorder. At post, 14 met criteria in the waitlist group and 0 in the treatment group. At baseline, per the inclusion criteria, all participants met criteria for nociplastic pain based on the Central Sensitization Inventory Part A total score. At post, 15 out of 16 participants from the wait-list group met criteria and 1 out of 11 from the treatment group met criteria.

\section{Discussion:}

It was hypothesized that the interdisciplinary treatment program would be a promising treatment approach for this population that often presents with persistent nociplastic pain, PTSD, anxiety, and/or depression. The results of this study indicate a significant reduction in all of the symptoms measured immediately post-treatment. This suggests that the interdisciplinary treatment program was effective for short-term reductions in symptoms of anxiety, depression, PTSD, nociplastic pain and functional problems.

The authors conjecture that the significant effect illustrated by this interdisciplinary treatment program for survivors of torture may be attributed to the coordinated and simultaneous provision of evidence-based physiotherapy and psychotherapy group interventions that aims to progress a client through stages of trauma recovery. Additionally, this treatment approach allows the client's physical and mental health to be addressed through a combination of interventions that aim to address biological, psychological, and social functioning which research has illustrated as essential to treating the complex conditions of PTSD, anxiety, depression, and pain (Asmundson et al., 2002).

The effectiveness of the treatment demonstrated in this study may also be attributed to the fact that aspects of the treatment are adapted to be relevant to the culture and context of the population. For example, a key component of the physiotherapy treatment is therapeutic neuroscience education which is a form of education that aims to change a person's thoughts and beliefs about their pain by teaching them about the biology that contributes to pain (Zimney et al., 2013). Previous research has recommended this treatment for persistent pain (Louw et al., 2016). However, many of the previously developed educational resources are designed in English and for a western-centric culture and context. Therefore, the physiotherapists delivering group physiotherapy treatment developed educational analogies, metaphors, stories, and pictures to be relevant to the culture, language, and context of treatment. These culturally and contextually adapted therapeutic neuro- 
Table 5. Measures at baseline and changes from pre-treatment (T0) to post-treatment (T1)

\begin{tabular}{|c|c|c|c|c|c|c|c|c|}
\hline & \multicolumn{2}{|c|}{$\begin{array}{l}\text { Treatment Group } \\
\text { At Baseline (T0) }\end{array}$} & \multicolumn{2}{|c|}{$\begin{array}{l}\text { Wait-list Group } \\
\text { At Baseline (T0) }\end{array}$} & \multicolumn{2}{|c|}{$\begin{array}{l}\text { Treatment } \\
\text { Group Change } \\
\text { (T0 to T1) }\end{array}$} & \multicolumn{2}{|c|}{$\begin{array}{l}\text { Wait-list } \\
\text { Group Change } \\
\text { (T0 to T1) }\end{array}$} \\
\hline & $\mathbf{M}$ & $\begin{array}{c}\text { IQR } \\
\left(1^{\mathrm{st},} \mathbf{3}^{\mathrm{rd}}\right)\end{array}$ & $\mathbf{M}$ & $\begin{array}{c}\text { IQR } \\
\left(1^{\text {st, }} 3^{\text {rd }}\right)\end{array}$ & $\mathbf{M}$ & $\begin{array}{c}\text { IQR } \\
\left(1^{\text {st, }} 3^{\text {rd }}\right)\end{array}$ & $\mathbf{M}$ & $\begin{array}{c}\text { IQR } \\
\left(1^{\mathrm{st},} \mathbf{3}^{\mathrm{rd}}\right)\end{array}$ \\
\hline \multicolumn{9}{|c|}{ Hopkins Symptoms Checklist $\mathbf{- 2 5}$} \\
\hline $\begin{array}{l}\text { Anxiety } \\
\text { Score }\end{array}$ & 3.0 & $2.1,3.1$ & 2.5 & $2.2,3.0$ & $1.3+\ddagger$ & $1.1,2.0$ & 0.1 & $-0.1 \cdot 0.7$ \\
\hline $\begin{array}{l}\text { DSM } \\
\text { IV De- } \\
\text { pression } \\
\text { Score }\end{array}$ & 2.8 & $2.3,3.2$ & 2.7 & $2.5,3.1$ & $1.8+\ddagger$ & $1.3,2.0$ & -0.0 & $-0.2,0.5$ \\
\hline $\begin{array}{l}\text { Total } \\
\text { Score }\end{array}$ & 2.8 & $2.3,3.1$ & 2.6 & $2.3,2.9$ & $1.8 \dagger \ddagger$ & $1.3,2.0$ & 0.0 & $-0.1,0.4$ \\
\hline
\end{tabular}

Harvard Trauma Questionnaire - Part 4

\begin{tabular}{lcccccccc}
\hline DSM - & 2.8 & $2.5,3.2$ & 2.7 & $2.4,3.0$ & $1.8 \dagger \neq$ & $1.4,2.0$ & -0.2 & $-0.5,0.2$ \\
IV Score & & & & & & & & \\
$\begin{array}{l}\text { Total } \\
\text { Score }\end{array}$ & 2.7 & $2.5,3.0$ & 2.7 & $2.5,2.8$ & $1.5 \dagger \neq$ & $1.4,1.7$ & -0.1 & $-0.4,0.1$ \\
\hline
\end{tabular}

\begin{tabular}{|c|c|c|c|c|c|c|c|c|}
\hline \multicolumn{9}{|c|}{ Central Sensitization Inventory Part A } \\
\hline $\begin{array}{l}\text { Total } \\
\text { Score }\end{array}$ & 57 & $\begin{array}{l}48.0 \\
62.0\end{array}$ & 53.0 & $44.0,65.0$ & $41.0 \dagger \ddagger$ & $\begin{array}{l}37.0 \\
45.0\end{array}$ & 1.5 & $-4.0,13.8$ \\
\hline \multicolumn{9}{|c|}{ Pittsburgh Sleep Quality Index } \\
\hline $\begin{array}{l}\text { Global } \\
\text { Score }\end{array}$ & 12 & $\begin{array}{l}10.0 \\
13.0\end{array}$ & 13.5 & $12.3,15.8$ & $9.0 \dagger \ddagger$ & $5.0,11$ & 3.0 & $-0.5,7.0$ \\
\hline \multicolumn{9}{|c|}{ General Self Efficacy Scale } \\
\hline $\begin{array}{l}\text { Total } \\
\text { score }\end{array}$ & 29 & $\begin{array}{l}20.0 \\
37.0\end{array}$ & 29.0 & $20.0,36.0$ & $-8.0 \dagger \ddagger$ & $\begin{array}{l}-14.0 \\
-1.0\end{array}$ & 2.0 & $-5.0,7.0$ \\
\hline
\end{tabular}

Patient-Specific Functional Scale (PSFS)

\begin{tabular}{lllllllll}
\hline Goal 1 & 1.0 & $0.0,4.0$ & 2.0 & $0.0,3.8$ & $-6.0 \dagger \ddagger$ & $-8.0,-4.0$ & 0.0 & $-2.0,0.0$ \\
Goal 2 & 3.0 & $0.0,5.0$ & 2.5 & $2.0,3.0$ & $-4.0 \dagger \ddagger$ & $-6.0,-3.0$ & 0.0 & $-1.8,0.0$ \\
Goal 3 & 3.0 & $2.0,3.0$ & 2.0 & $0.0,4.0$ & $-6.0 \dagger \ddagger$ & $-6.0,-2.0$ & -0.5 & $-2.0,0.0$
\end{tabular}

Note. $M=$ Median. IQR $=$ Interquartile range. $1^{\text {st }}=$ The first quartile. $3^{\text {rd }}=$ The third quartile.

$\dagger p<.01$ within-group difference $\mathrm{T} 0$ to $\mathrm{T} 1$

$\ddagger \mathrm{p}<.01$ between-group difference compared to Wait-List Group 
science education resources are integrated into the studied treatment service.

It is important to recognize that the participants in the study continued to live within the prison without changes to their sentences or living conditions and with ongoing exposure to the stress and trauma of these conditions. Therefore, this study indicates that it may be possible to address symptoms of mental and physical health in contexts where the ongoing stress cannot be abolished. Previous research has established that various factors contribute to a person's ability to remain resilient and have limited deleterious effects on health in the face of ongoing stress and trauma (Sareen, 2014). The authors surmise that the treatment service used in the present study equips persons with adaptive beliefs and coping strategies that allows them to better self-manage stress and other factors contributing to poor functioning.

This pilot study allows the researchers to explore the feasibility of conducting internationally recognized treatment approaches and research within the context of a prison in Kurdistan, a post-conflict area, with local healthcare professionals. The successful implementation of this study is a positive indicator of what is possible in this setting. This pilot study proved feasible most likely as a result of the authors' and Wchan's trusted relationships, social capital, and its commitment to and engagement with local stakeholders, including prison leadership, government, and the participant population. The authors also recognize that capacity building activities designed to equip Wchan's clinical team with the skills to deliver internationally recognized research practices was required to conduct this study effectively. The members of the clinical team participated in an estimated 20 hours of training to build their skills in research ethics and principles and procedures of data collec- tion and data management. Additionally, they participated in an estimated 15 hours of interdisciplinary team discussion during the study and an estimated 30 hours of direct clinical supervision of the data collection and treatment interventions. International research partners provided external review and consultation, resources for research, and statistical analyses.

The feasibility of future research was also strengthened by participant compliance. Compliance was excellent as demonstrated by an $88.43 \%$ attendance rate for the group treatment service, after removing the one dropout within this group. Participants never reported not attending the group due to disinterest, but rather the most common reasons for absence were being required to work within the prison, acute illness, and legal procedures. Only three dropouts occurred over the span of the study with the reasons for drop-out not being related to the individual's dislike or disinterest in the treatment service (see Figure 1). Based on the experience of this pilot study, it would be feasible to implement a future large-scale controlled study. Recommended amendments for a future definitive trial include validating Kurdish versions of all measures, implementing blinding procedures and long-term follow up measures, and including several arms within the trial so that a comparison can be made between the impact of discipline specific treatment and the interdisciplinary treatment program.

\section{Limitations}

The study has some important limitations: the small sample size limits generalizability of results. In addition, this study lacked longterm follow-up limiting the extent to which long-term effects of the treatment can be evaluated. The authors also recognize additional limitations in the study design. Bias in the data collection and reporting is possible 
given this study was not blinded and relied on self-reported outcomes. Also, despite being validated in other settings, several of the Kurdish Sorani versions of the outcome measures were not validated for use in the current study setting. Finally, based on the small sample size and study design, it is not possible to identify which aspect of the treatment services have a more significant effect and whether the interdisciplinary nature of the program is more beneficial than one discipline. Lastly, feasibility of a few components that would be required for a large-scale study were not explored including blinding procedures and long-term follow up measures.

\section{Conclusion}

This pilot study provides preliminary evidence for the effectiveness of culturally- and contextually-appropriate interdisciplinary physiotherapy and psychotherapy group treatment approach for survivors of torture in a male prison in Kurdistan. It also demonstrates the feasibility of implementing research that follows international research standards and practices within under-researched settings like prisons and post-conflict areas. A large scale randomized controlled study is warranted and feasible to further examine the treatment effects of this approach, as well as, to examine the long-term impact of the treatment.

\section{Acknowledgements:}

Michael Shoemaker PT, DPT, PhD. Supported study design, data analysis, and writing.

Research Team (in alphabetical order):

Dara Faiq Abdalrahman

Chro Qadr Muhamad Ameen

April Gamble

Hiwa Omer Ismail

Salah Hassan Rahim

Yadgar Ismaiel Mohamed
Ahmed Amin Mohammed

Mohammed Azeez Raheem

Goran Mohamad Rasool

Sarwar Kareem Saeed

Fariq Karim Saeed

Kawa Peshraw Salih

Mina Harith Zaki

\section{Funding:}

Service provision for survivors of torture that participated in this study is supported by United Nations Human Rights - United Nations Voluntary Fund forVictims of Torture

\section{References}

Amnesty international ltd. (2014). Torture in 2014 30 Years of Broken Promises. Torture in 2014 - 30 Years of Broken Promises (pp. 1-50). London.

Amris, K., \& Williams, A. C. D. C. (2015). Managing chronic pain in survivors of torture. Pain Management, 5(1), 5-12. doi: 10.2217/pmt.14.50

Asmundson, G. J., \& Katz, J. (2009). Understanding the co-occurrence of anxiety disorders and chronic pain: state-of-the-art. Depression and Anxiety, 26(10), 888-901. doi: 10.1002/da.20600

Asmundson, G. J., Coons, M. J., Taylor, S., \& Katz, J. (2002). PTSD and the Experience of Pain: Research and Clinical Implications of Shared Vulnerability and Mutual Maintenance Models. The Canadian Fournal of Psychiatry, 47(10), 930-937. doi: 10.1177/070674370204701004

Bair, M. J., Robinson, R. L., Katon, W., \& Kroenke, K. (2003). Depression and Pain Comorbidity. Archives of Internal Medicine, 163(20), 2433. doi: 10.1001/ archinte.163.20.2433

Breivik, H., Eisenberg, E., \& O’Brien, T. (2013). The individual and societal burden of chronic pain in Europe: the case for strategic prioritisation and action to improve knowledge and availability of appropriate care. BMC Public Health, 13(1). doi: 10.1186/1471-2458-13-1229

Bunn, M., Goesel, C., Kinet, M., \& Ray, F. (2016). Group treatment for survivors of torture and severe violence: A literature review. Torture fournal, 26(1), 23. doi: 10.7146/torture. v26i1.108062

Convention against Torture and Other Cruel, Inhuman or Degrading Treatment or Punishment - Addendum to Initial reports of States parties 
due in 1995 (PDF). U.S. Department of State. U.S. Department of State.

Darnall, B. D., \& Sazie, E. (2012). Pain Characteristics and Pain Catastrophizing in Incarcerated Women with Chronic Pain. Fournal of Health Care for the Poor and Underserved, 23(2), 543-556. doi: 10.1353/hpu.2012.0042

Dibaj, I., Halvorsen, J. Ø., Kennair, L. E. O., \& Stenmark, H. I. (2017). An evaluation of combined narrative exposure therapy and physiotherapy for comorbid PTSD and chronic pain in torture survivors. Torture fournal, 27(1). doi: 10.7146/torture.v27i1.26534

Dirkzwager, A. J. E. (2019). The longitudinal course of prisoners' mental health problems during and after imprisonment. European fournal of Public Health, 29(Supplement_4). doi: 10.1093/eurpub/ ckz185.759

Fazel, S., \& Danesh, J. (2002). Serious mental disorder in 23000 prisoners: a systematic review of 62 surveys. The Lancet, 359(9306), 545-550. doi: 10.1016/s0140-6736(02)07740-1

Fazel, S., \& Seewald, K. (2012). Severe mental illness in 33588 prisoners worldwide: systematic review and meta-regression analysis. British fournal of Psychiatry, 200(5), 364-373. doi: 10.1192/bjp. bp. 111.096370

Fazel, S., Hayes, A. J., Bartellas, K., Clerici, M., \& Trestman, R. (2016). Mental health of prisoners: prevalence, adverse outcomes, and interventions. The Lancet Psychiatry, 3(9), 871881. doi: 10.1016/s2215-0366(16)30142-0

Gifford, E. J. (2019). How Incarceration Affects the Health of Communities and Families. North Carolina Medical fournal, 80(6), 372-375. doi: $10.18043 / \mathrm{ncm} .80 .6 .372$

Heartland Alliance International. (2015). Torture and ill-treatment in detainees in Iraq and the Iraqi Kurdistan Region - A Report on Prevalence and Practice. Torture and ill-treatment in detainees in Iraq and the Iraqi Kurdistan Region - A Report on Prevalence and Practice (pp. 1-80). Chicago, IL .

Heckman, C. J., Cropsey, K. L., \& Olds-Davis, T. (2007). Posttraumatic stress disorder treatment in correctional settings: A brief review of the empirical literature and suggestions for future research. Psychotherapy: Theory, Research, Practice, Training, 44(1), 46-53. doi: 10.1037/00333204.44.1.46

Horn KK, Jennings S, Richardson G, Vliet DV, Hefford C, Abbott JH. The patient-specific functional scale: psychometrics, clinimetrics, and application as a clinical outcome measure. J Orthop Sports Phys Ther. 2012 Jan;42(1):30-42. doi: 10.2519/jospt.2012.3727. Epub 2011 Oct
25. PMID: 22031594.

IASP Terminology. (2017, December 14). https:// www.iasp-pain.org/Education/Content. aspx?ItemNumber $=1698$

Kabengele, E. M., Chastonay, P., \& Frey, C. (2014). Economic burden of torture for a refugee host country: development of a model and presentation of a country case study. ClinicoEconomics and Outcomes Research, 165. doi: $10.2147 /$ ceor.s56431

Kinner, S. A., \& Young, J. T. (2018). Understanding and Improving the Health of People Who Experience Incarceration: An Overview and Synthesis. Epidemiologic Reviews, 40(1), 4-11. doi: 10.1093/epirev/mxx018

Kurklinsky, S., Perez, R. B., Lacayo, E. R., \& Sletten, C. D. (2016). The Efficacy of Interdisciplinary Rehabilitation for Improving Function in People with Chronic Pain. Pain Research and Treatment, 2016, 1-6. doi: 10.1155/2016/7217684

Leder, D. (2018). Coping with chronic pain, illness and incarceration: what patients and prisoners have to teach each other (and all of us). Medical Humanities, 44(2), 113-119. doi: 10.1136/ medhum-2017-011426

Loughran, M., \& King, T. (2004). Developing Prison Inreach Services for Female Prisoners. Mental Health Review fournal, 9(2), 34-37. doi: 10.1108/13619322200400020

Louw, A., Zimney, K., Puentedura, E. J., \& Diener, I. (2016). The efficacy of pain neuroscience education on musculoskeletal pain: A systematic review of the literature. Physiotherapy Theory and Practice, 32(5), 332-355. doi: 10.1080/09593985.2016.1194646

Mayer, TG, Neblett, R, Cohen, H, Howard, KJ, Choi, YH, Williams, MJ, Perez, Y, Gatchel, RJ. The Development and Psychometric Validation of the Central Sensitization Inventory (CSI). Pain Pract 2012; 12(4): 276-85.

Massoglia, M. (2008). Incarceration as Exposure: The Prison, Infectious Disease, and Other Stress-Related Illnesses. Fournal of Health and Social Behavior, 49(1), 56-71. doi: 10.1177/002214650804900105

Mcgeary, D., Moore, M., Vriend, C. A., Peterson, A. L., \& Gatchel, R. J. (2011). The Evaluation and Treatment of Comorbid Pain and PTSD in a Military Setting: An Overview. Fournal of Clinical Psychology in Medical Settings, 18(2), 155-163. doi: 10.1007/s10880-011-9236-5

McKernan, Lindsey C. PhD; Johnson, Benjamin N. MS; Crofford, Leslie J. MD; Lumley, Mark A. PhD; Bruehl, Stephen PhD; Cheavens, Jennifer S. PhD ${ }^{\#}$ Posttraumatic Stress Symptoms Mediate 
the Effects of Trauma Exposure on Clinical Indicators of Central Sensitization in Patients With Chronic Pain, The Clinical fournal of Pain: May 2019 - Volume 35 - Issue 5 - p 385-393 doi: 10.1097/AJP.0000000000000689

Mollayeva T, Thurairajah P, Burton K, Mollayeva S, Shapiro CM, Colantonio A. The Pittsburgh sleep quality index as a screening tool for sleep dysfunction in clinical and non-clinical samples: A systematic review and meta-analysis. Sleep Med Rev. 2016 Feb;25:52-73. doi: 10.1016/j. smrv.2015.01.009. Epub 2015 Feb 17. PMID: 26163057.

Olsen, D. R., Montgomery, E., Bøjholm, S., \& Foldspang, A. (2007). Prevalence of pain in the head, back and feet in refugees previously exposed to torture: A ten-year follow-up study. Disability and Rehabilitation, 29(2), 163171. doi: 10.1080/09638280600747645

Penal Reform International. (2015). Global Prison Trends 2015. Global Prison Trends 2015(pp. 1-44). London

Rasmussen A, Verkuilen J, Ho E, Fan Y. Posttraumatic stress disorder among refugees: Measurement invariance of Harvard Trauma Questionnaire scores across global regions and response patterns. Psychol Assess. 2015;27(4):1160-1170. doi: $10.1037 /$ pas0000115

Sareen, J. (2014). Posttraumatic Stress Disorder in Adults: Impact, Comorbidity, Risk Factors, and Treatment. The Canadian Fournal of Psychiatry, 59(9), 460-467. doi: $10.1177 / 070674371405900902$

Schwarzer, R., \& Jerusalem, M. (1995). Generalized Self-Efficacy scale. In J. Weinman, S. Wright, \& M. Johnston, Measures in health psychology: A user's portfolio. Causal and control beliefs (pp. 35-37). Windsor, UK: NFER-NELSON.

Steel, Z., Chey, T., Silove, D., Marnane, C., Bryant, R. A., \& Ommeren, M. V. (2009). Association of Torture and Other Potentially Traumatic Events With Mental Health Outcomes Among Populations Exposed to Mass Conflict and Displacement. Fama, 302(5), 537. doi: 10.1001/ JAMA.2009.1132

Tay, A., Jayasuriya, R., Jayasuriya, D. et al. Measurement invariance of the Hopkins Symptoms Checklist: a novel multigroup alignment analytic approach to a large epidemiological sample across eight conflictaffected districts from a nation-wide survey in Sri Lanka. Confl Health 11, 8 (2017). https://doi. org/10.1186/s13031-017-0109-x

Tsang, A., Korff, M. V., Lee, S., Alonso, J., Karam, E., Angermeyer, M. C., ... Watanabe, M. (2008).
Common Chronic Pain Conditions in Developed and Developing Countries: Gender and Age Differences and Comorbidity With DepressionAnxiety Disorders. The fournal of Pain, 9(10), 883-891. doi: 10.1016/j.jpain.2008.05.005

Tsur, N., Defrin, R., \& Ginzburg, K. (2017). Posttraumatic Stress Disorder, Orientation to Pain, and Pain Perception in Ex-Prisoners of War Who Underwent Torture. Psychosomatic Medicine, 79(6), 655-663. doi: 10.1097/ psy.0000000000000461

Tsur, N., Shahar, G., Defrin, R., Lahav, Y., \& Ginzburg, K. (2017). Torturing personification of chronic pain among torture survivors. Fournal of Psychosomatic Research, 99, 155-161. doi: 10.1016/j.jpsychores.2017.06.016

United Nations: Draft Convention Against Torture and Other Cruel, Inhuman or Degrading Treatment or Punishment. (1984). International Legal Materials, 23(5), 1027-1037. doi: 10.1017/ s0020782900030990

Weiss, W. M., Uguento, A. M., Mahmooth, Z., Murray, L. K., Hall, B. J., Nadison, M., ... Bolton, P. (2018). Mental health interventions and priorities for research for adult survivors of torture and systematic violence: a review of the literature. Torture fournal, 26(1), 27. doi: 10.7146/torture.v26i1.108061

Wildeman, C., Goldman, A. W., \& Lee, H. (2019). Health Consequences of Family Member Incarceration for Adults in the Household. Public Health Reports, 134(1_suppl). doi: 10.1177/0033354918807974

Williams, A. C. D. C., Peña, C. R., \& Rice, A. S. (2010). Persistent Pain in Survivors of Torture: A Cohort Study. Fournal of Pain and Symptom Management, 40(5), 715-722. doi: 10.1016/j. jpainsymman.2010.02.018

Williams, B. A., Ahalt, C., Stijacic-Cenzer, I., Smith, A. K., Goldenson, J., \& Ritchie, C. S. (2014). Pain Behind Bars: The Epidemiology of Pain in Older Jail Inmates in a County Jail. fournal of Palliative Medicine, 17(12), 1336-1343. doi: 10.1089/jpm.2014.0160

Yoon, I. A., Slade, K., \& Fazel, S. (2017). Outcomes of psychological therapies for prisoners with mental health problems: A systematic review and meta-analysis. Fournal of Consulting and Clinical Psychology, 85(8), 783-802. doi: 10.1037/ ccp0000214

Zimney, K., Louw, A., \& Puentedura, E. J. (2013). Use of Therapeutic Neuroscience Education to address psychosocial factors associated with acute low back pain: a case report. Physiotherapy Theory and Practice, 30(3), 202-209. doi: 10.3109/09593985.2013.856508 